\title{
ОТХОДЫ ПРОИЗВОДСТВА: АКТУАЛЬНЫЕ ВОПРОСЫ И ТЕХНИКО-ЭКОНОМИЧЕСКОЕ ОБОСНОВАНИЕ ВНЕДРЕНИЯ РЕСУРСОСБЕРЕГАЮЩИХ ТЕХНОЛОГИЙ
}

\author{
(c) 2019 Бариленко Владимир Иванович
}

доктор экономических наук, профессор Департамента учета, анализа и аудита Финансовый университет при Правительстве Российской Федерации E-mail:vbarilenko@fa.ru

(c) 2019 Никифорова Елена Владимировна

доктор экономических наук, профессор Департамента учета, анализа и аудита Финансовый университет при Правительстве Российской Федерации

E-mail:EVNikiforova@fa.ru

В статье раскрывается значимость ресурсосберегающих технологий предприятия, снижающих уровень отходов в производственном процессе, что в свою очередь снижает затратоёмкость, повышает уровень его конкурентоспособности и финансовую устойчивость. Фактором высокого уровня конкурентоспособности любого предприятия является его безотходная деятельность, положительно влияющая на финансовый результат за счет эффективного использования ресурсов.

Ключевые слова: отходы, технологии, ресурсосбережение, экономическое обоснование, производство, затраты, финансовая устойчивость, финансовый результат, фактор, эффективность.

Проблема обеспечения рационального обращения с отходами производства и потребления затрагивает все три основные аспекта создания условий устойчивого развития - и экономический, и социальный, и экологический аспекты.

Но сложившееся к настоящему времени в нашей стране положение в сфере образования отходов, их переработки, вовлечения в хозяйственный оборот и полезного использования или безопасного хранения можно считать недопустимым. Оно приводит к неразумному использованию природных ресурсов, огромным экономическим потерям, ухудшению экологической ситуации и социальных условий жизни населения, возникновению опасностей для здоровья как ныне живущих, так и будущих поколений россиян.

Важность решения этой проблемы остро проявилась более двадцати лет назад с принятием Федерального закона от 24.06.1998 № 89Ф3 «Об отходах производства и потребления» [1]. Закон определил правовые основы обращения с отходами в целях предотвращения их вредного воздействия на природную среду и здоровье населения, а также вовлечения отходов в хозяйственный оборот страны в качестве дополнительных материальных ресурсов.

В контексте этого закона отходами считаются утратившие при использовании в процес- се производства или потребления свои первоначальные потребительские свойства остатки сырья, материалов, полуфабрикатов, комплектующих изделий, иных изделий или продуктов. Повторное полезное использование подобных ресурсов представляет собой гигантский резерв развития экономики. Однако действенного механизма реализации требований законодательства в данной сфере до настоящего времени не было создано. Для решения этой проблемы необходима разработка комплексных мер общенационального масштаба.

Так, указом Президента Российской Федерации от 14.01.2019 № 8 Министерству природных ресурсов и экологии РФ поручено учредить публично-правовую государственную компанию «Российский экологический оператор», которая должна выстроить общероссийскую комплексную систему обращения с твердыми коммунальными отходами [2]. Российский экологический оператор призван обеспечить эффективное управление процессами сбора, хранения, утилизации и переработки бытовых отходов в нашей стране на основе взаимодействия с ранее созданными аналогичными региональными операторами и комплексного контроля их деятельности. Для организации такого контроля Правительству РФ вменено в обязанность до 01.01.2020 г. обеспечить формирование еди- 
ной государственной системы учета твердых коммунальных отходов. Такая система должна быть создана на базе интеграции региональных информационных систем отражения данных об обращении с твердыми бытовыми отходами, собираемых при помощи средств автоматизированного технического контроля объемов их перемещения, утилизации и хранения.

Но при том, что деятельность отечественных производственных организаций характеризуется заведомо излишними объемами плохо используемых отходов, подобные меры не предусматриваются для отходов производства. Это затрудняет не только контроль обращения с производственными отходами, но и информационное обеспечение аналитического обоснования мер по внедрению ресурсосберегающих технологий, совершенствованию процессов утилизации отходов.

Степень использования методов ресурсосбережения в процессах производства продукции является важным фактором не только сокращения отходов производства, но и повышения конкурентоспособности, снижения себестоимости и роста финансовой результативности организаций производственной сферы, укрепления их финансовой устойчивости.

«По мере преодоления последствий глобального кризиса все более очевидным становится тот факт, что мировая экономика находится на пороге новой волны роста инвестиций в основной капитал, направляемых на повышение качества национальных экономик. Причем будущий новый социально экономический уклад предполагает широкое внедрение ресурсосберегающих технологий» [3, с. 18-23].

Очевидно, любой субъект хозяйствования должен уделять повышенное внимание аналитическому обоснованию внедрения конкретных ресурсосберегающих технологий, понимая их роль в обеспечении устойчивости своей деятельности.

Важность вопросов безотходного производства подтверждается тем, что «рациональное и комплексное использование сырьевых ресурсов имеет решающее значение, так как в настоящее время в конечный продукт включается в среднем лишь около 10\% массы используемых природных ресурсов, а остальные 90\% теряются» [4].

Ресурсосбережение можно понимать как уровень ресурсозатрат на единицу товарной продукции или единицу её стоимости. Ресурсосбережение в технологии базируются на трех основных направлениях (рисунок 1).

Особенностью каждого из вышеперечисленных направлений ресурсосбережения является то, что по каждому из этих направлений необходимо вести поисковые научные исследования, экспериментальные работы и промышленную апробацию. Это необходимо для того, чтобы, выявив все недостатки и достоинства используемых технологий, приступить к созданию новых или совершенствованию используемых технологий.

Р.И. Хансевяров считает «содержание ресурсосбережения определяют как процесс: устра-

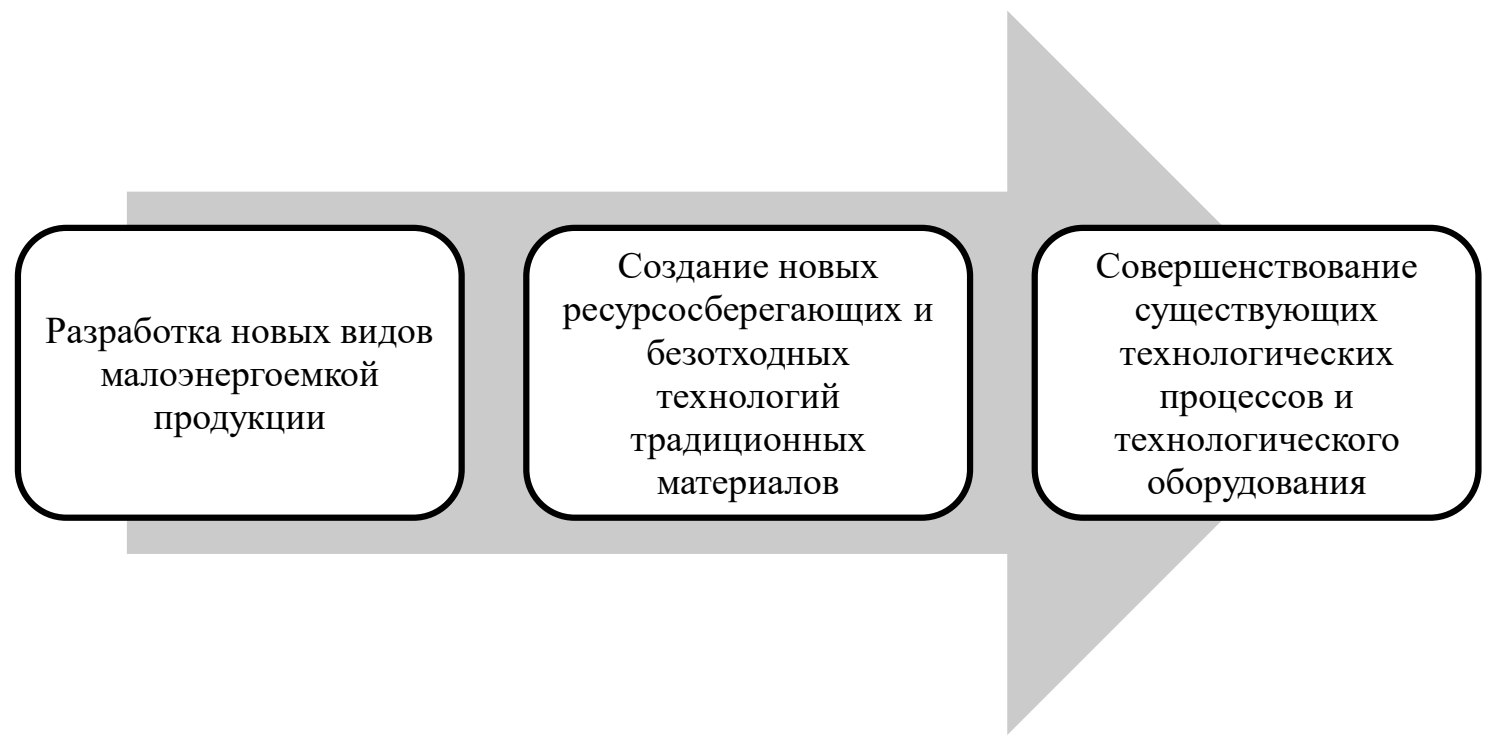

Рис.1. Основные направления ресурсосбережения в технологическом процессе 
нения потерь; задействования неиспользуемых резервов; повышения эффективности потребления факторов производства; интенсификации потребления факторов производства; уменьшения ущерба; снижения дефицита факторов производства» [5].

В последнее время мировое сообщество большое внимание уделяет вопросам сохранения окружающей среды и влиянию используемых технологий на нее. Несомненно, решение проблем внедрения безотходных или малоотходных технологий не должно осуществляться без учета связанных с ними экологических и социальных проблем.

Безотходная технология является идеальной моделью производства. Но в настоящее время выделяют безотходные и малоотходные технологии. Особенность безотходной технологии определяется полным использованием ресурса в процессе производства без его негативного влияния на внешнюю среду. Безотходная технология характеризуется всемерно возможной утилизацией образовавшихся в прямых технологических процессах отходов [6].

Малоотходные технологии обеспечивают получение продукта с неполной утилизацией отходов его производства. Такая технология является промежуточной ступенью безотходной технологии, когда отходы производства, относящиеся к вторичным материальным ресурсам, подвергаются переработке для их повторного использования.

Современные безотходные технологии развиваются в четырех направления (рисунок 2).

В качестве объектов ресурсосбережения экономических субъектов выделяют финансовые, материальные, временные, трудовые, техноло- гические и энергетические ресурсы.

Далее обратим внимание на многообразие факторов ресурсосбережения, имеющих свою долю влияния на конечный результат финансово-хозяйственной деятельности субъекта хозяйствования. Основные факторы ресурсосбережения можно разделить на три группы (рисунок 3): технические, организационные, социально-экономические, при этом не стоит забывать об очень важном факторе ресурсосбережения - о нормировании.

Под нормированием в данном случае понимается предварительный анализ эффективного использования ресурса на основе внедрения технических и организационных мер ресурсосбережения, разработанных, технически обоснованных, согласованных и утвержденных норм расхода этого ресурса на единицу продукции, работ либо их элементов.

Технически обоснованная норма расхода представляет собой максимально допустимое при использовании прогрессивной технологии количество материалов для производства единицы работ или готовой продукции с учетом как нормы «чистого» расхода, так и нормы допустимых отходов и нормы неизбежных потерь материалов в процессе производства. Основные требования по разработке норм расхода представлены на рисунке 4 .

Использование закона эффекта масштаба производства является немаловажным фактором ресурсосбережения. Это связано в первую очередь с тем, что увеличение масштаба производства расширяет возможности применения ресурсосберегающих технологий, сокращая тем самым потери материальных ресурсов.

Тибилов Д.П., Савон Д.Ю. утверждают «Ме-

Создание бессточных технологических систем с целью уменьшения потребления воды

Разработка и внедрение систем переработки отходов производства и потребления, т.е. получение вторичных материальных ресурсов
Направления развития

современных безотходных технологий
Организация и внедрение новых усовершенствованных технологических процессов, позволяющих сократить количество отходов и этапы переработки
Разработка и создание территориальнопромышленных комплексов с замкнутой структурой материальных потоков сырья и отходов внутри такого комплекса 
Технические факторы: применение технологий, обеспечивающих минимальные потери материалов; применение оборудования, требуюшего оптимального расхода материалов; улучшение качества применяемых ресурсов и создание материалов с заранее заданными свойствами; совершенствование технической базы транспортирования и хранения ресурсов; совершенствование технологических режимов переработки сырья; создание экспериментальной базы для моделирования расхода ресурсов

\section{Организационные факторы:}

совершенствование организации учета получения и использования ресурсов; сокращение цикла от получения до использования ресурсов; повышение качества ремонта технологического оборудования; совершенствование организации производства и труда с целью экономии ресурсов; организация вторичного использования ресурсов; разработка и внедрение организационно-технических мероприятий по экономии ресурсов

\section{Социально-экономические факторы: анализ действия закона масштаба, закона экономии времени в сложившихся условиях; применение к управлению ресурсами научных походов менеджмента; применение методов ФСА, прогнозирования, ЭММ; улучшение условий труда и отдыха работников; применение мер стимулирования и ответственности за экономию; осуществление социально- психологических мероприятий по экономии}

Puc. 3. Факторы, оказывающие влияние на уровень ресурсосбережения

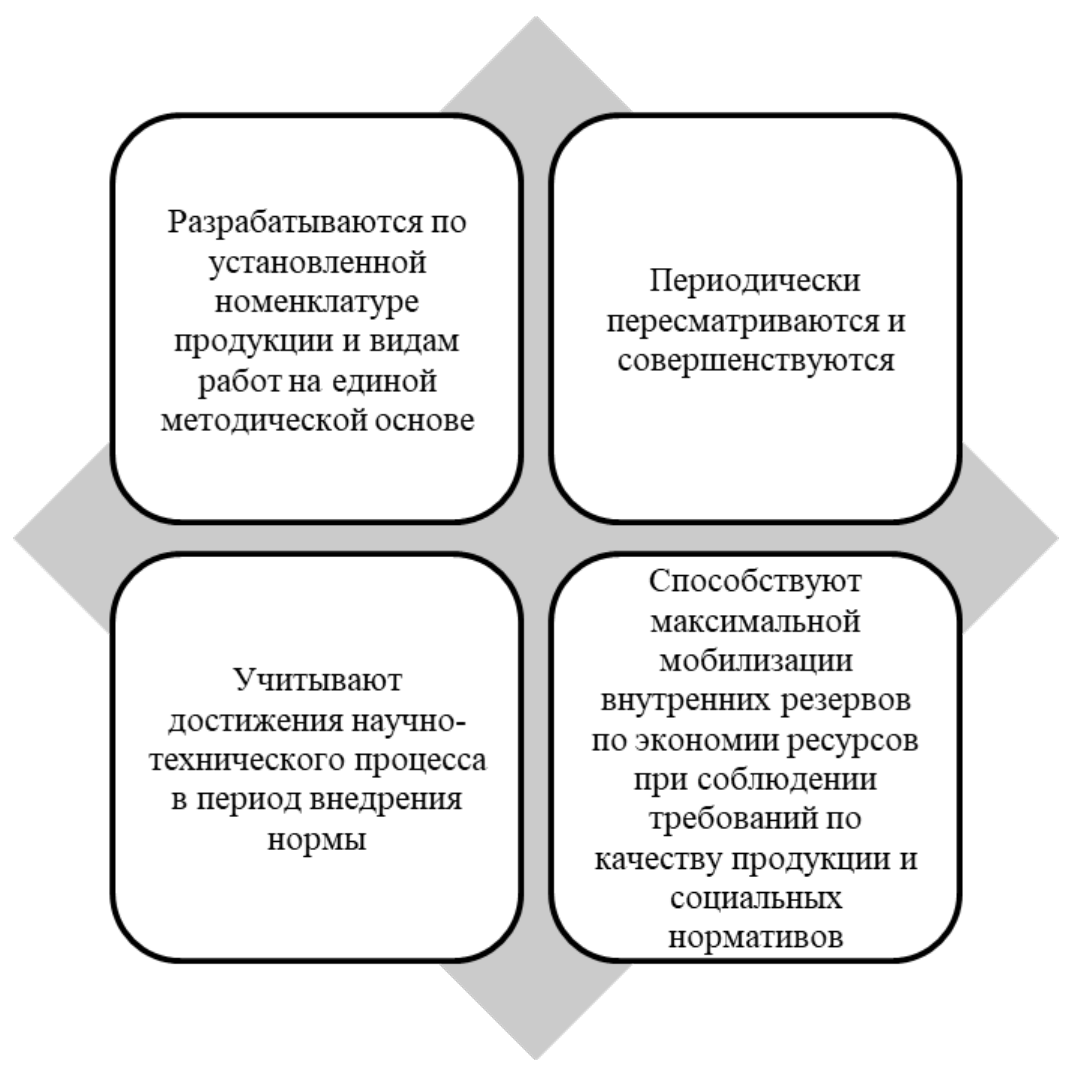

Puc. 4. Требования к разработке норм расхода 
ханизм интегрированного процесса перехода промышленных предприятий к ресурсосберегающим технологиям при стремлении к устойчивому развитию заключается в возрастании роли экономического стимулирования в обеспечении процесса ресурсосбережения» [7]. «Эффективность механизма ресурсосбережения зависит от функциональной полноты системы, то есть от сущности функций, которые способны обеспечить дальнейшее развитие предприятия» [8].

Следует заметить, что показатели ресурсосбережения относят к важным показателям наряду с ценой, качеством и конкурентоспособностью продукции. С другой точки зрения показатели ресурсосбережения отражают индивидуальные свойства товара в части его технического совершенствования, а именно: степени экономного потребления трудовых, материальных, финансовых и энергоресурсов, ориентируясь на степень экономного использования ресурсов и их ёмкости.
Стоит заметить, что при анализе уровня ресурсосбережения ориентируются на технико-экономические показатели, которые в свою очередь являются измерителями, характеризующими материально-производственную базу и комплексное использование ресурсов предприятия. Технико-экономические показатели используются в процессе планирования, производства, контроля, анализа и принятия управленческих решений. При этом могут использоваться как универсальные технико-экономические показатели, общие для всех предприятий и отраслей, так и специфические, отражающие особенности отдельных отраслей.

Рациональное использование ресурсов, обеспечение защиты окружающей среды и решение социальных вопросов выходят на первые места в оценке деятельности любого участника бизнеса, обеспечивая эффективное управление их долгосрочной конкурентоспособностью и устойчивостью развития.

\section{Библиографический список}

1. Федеральный закон от 24.06.1998 № 89-ФЗ (ред. от 25.12.2018) «Об отходах производства и потребления».

2. Указ Президента Российской Федерации от 14.01.2019 № 8 «О создании публично-правовой компании по формированию комплексной системы обращения с твердыми коммунальными отходами «Российский экологический оператор».

3. Быков П., Гурова Т. Что не обсуждали в Давосе // Эксперт. - 2010. - № 5. - С. 16-23.

4. Экологический портал. https://www.aboutecology.ru/prirodopolzovanie/bezothodnaya

5. Хансевяров Р.И. Ресурсосбережение как фактор повышения эффективности производства // Экономика и управление 2011. № 6 (79). С. 50-53.

6. Богатырев А.В. Теория и методология организационно-экономического обеспечения ресурсосбережения на промышленных предприятиях//иссертация на соискание степени доктора экономических наук по специальности 08.00.05 - Экономика и управление народным хозяйством: экономика, организация и управление предприятиями, отраслями, комплексами (промышленность).- Нижний Новгород: Нижегородский государственный университет им. Н.И. Лобаческого, 2010.

7. Тибилов Д. П., Савон Д. Ю. Экономические аспекты процесса перехода на ресурсосберегающие технологии промышленными предприятиями // Горный информационно-аналитический бюллетень. 2015. № 5 . С. 285-290.

8. Белопольская Т.В., Ярошенко А.В. Методологические основы формирования механизма ресурсосбережения на предприятии // Вестник института экономических исследований 2018, № 3(11). 